\title{
CLONINGER'S TEMPERAMENT AND CHARACTER DIMENSIONS AND DOPAMINERGIC GENES: DAT1 VNTR AND COMT VAL158MET POLYMORPHISMS
}

\author{
Ivana Glavina Jelaš ${ }^{1}$, Ivan Dević ${ }^{2} \&$ Dalibor Karlović ${ }^{3}$ \\ ${ }^{I}$ Police College, Zagreb, Croatia \\ ${ }^{2}$ Ivo Pilar Institute of Social Sciences, Zagreb, Croatia \\ ${ }^{3}$ Sestre Milosrdnice University Hospital, Zagreb, Croatia
}

received: 30.10.2017;

revised: 15.12.2017;

accepted: 29.12 .2017

\section{SUMMARY}

Background: the objective of this study was to examine the associations between Cloninger temperament and character dimensions with the DAT1 VNTR and COMT Val158Met polymorphisms.

Subjects and methods: The study was conducted on 101 subjects, consisting of students of the Police College in Zagreb and staff of the Sestre Milosrdnice University Hospital in Zagreb. The Cloninger Temperament and Character Inventory (TCI) was used to test personality traits.

Results: A main effect of the DAT1 VNTR polymorphism was found on the subscale self-directedness $-S D 2(F=5.18, d f=1$, $p<0.05)$, where a higher result was detected in carriers of the 9/9 genotype $(M=7.33, S D=0.51)$ than those carrying the 10-repeat allele $(M=6.02, S D=1.36)$. Also for the COMT Val158Met polymorphism, main effects were found on the subscales: NS3 (novelty seeking) $(F=5.18, d f=1, p<0.05)$, where a higher result was found in carriers of the Val allele $(M=5.03, S D=2.22)$ than in carriers of the Met/Met genotype ( $M D=4.76, S D=2.37), S D 3$ (self-directedness) $(F=5.18, d f=1, p<0.05)$ where a higher result was found in carriers of the Val/Val genotype $(M=4.50, S D=0.78)$ than in those carrying the Met allele $(M=3.80, S D=1.31)$; $C 3$ (cooperativeness) $(F=5.18, d f=1, p<0.05)$, where a high result was found in carriers of the Val allele $(M=5.68, S D=1.25)$ than those carrying the Met/Met genotype $(M=5.08, S D=1.11)$; and $S T 3$ (self-transcendence) $(F=5.18, d f=1, p<0.05)$, where a higher result was found in carriers of the Met/Met genotype $(M=3.46, S D=2.37)$ than carriers of the Val allele $(M=2.69, S D=1.84)$. Two significant interactions were detected, on the subscale NS3 (novelty seeking) $(F=5.18, d f=1, p<0.05)$, and on the subscale C2 (cooperativeness) $(F=5.18, d f=1, p<0.05)$.

Conclusions: Cloninger's (1987) hypothesis about negative relationship between novelty seeking and dopamine was confirmed on allele level, because higher novelty seeking was found in Val allele carriers comparing to Met/Met genotype carriers.

Key words: personality - DAT1 VNTR - COMT Val158Met - Cloninger - dopaminergic genes

\section{INTRODUCTION}

It is generally assessed that the heritability of personality ranges from $30 \%$ to $50-60 \%$ (Bouchard \& Loehlin 2001, Larsen \& Buss 2005). Assessments vary due to different methodologies, study designs and personality models used (Vukasović 2013).

In molecular and genetic research that aims to determine a specific gene associated with specific personality traits, the genes of the dopamine and serotonin systems are the most commonly studied. One of the most commonly studied of the dopamine genes are DAT1 VNTR and COMT Val158Met polymorphisms. In measuring personality, the Cloninger Temperament and Character Inventory (TCI) test is most commonly used. This model includes four temperament traits: novelty seeking, harm avoidance, reward dependence and persistence, and three character traits: self-directedness, cooperativeness and self-transcendence. Cloninger (1987) associated a higher novelty seeking trait with a lower level of dopamine. Harm avoidance was associated with serotonin, though it has been stated that it is not recommended to assume a simple linear relationship with absolute serotonin levels (Larsen \& Bus 2008). A higher reward dependence is associated with low levels of noradrenaline. Persistence has not been associated with specific neurotransmitters.

In terms of the dopamine system, important indicators are the dopamine transporter (DAT) and catecholO-methyltransferase (COMT). DAT carries dopamine from the synapse into the presynaptic neuron, while COMT participates in dopamine breakdown, and therefore affects its overall levels.

The gene that codes DAT is the SLC6A3 gene (or DAT1), which is found on the short arm of the 5th chromosome, at the site $5 \mathrm{p} 15.3$. It contains approximately 52,637 nucleotides and 15 exons consisting of 3932 nucleotides (Mrazek 2010). The best known gene variation is rs 28363170 or DAT1 VNTR or $40 \mathrm{bpVNTR}$ at 3'UTR, which implies a certain number of repetitions of a block of 40 base pairs. The differences in VNTR affect the level of expression of DAT1, i.e. the amount of DAT protein, which in turn affects dopamine levels. The polymorphism has two common alleles, with 9 or 10 repetitions of the 40 base pair block. There are alleles with 3 to 11 repetitions of the base pair block, 
though these are less commonly studied (van Dyck et al. 2005). Numerous studies have examined the relationship of DAT proteins and dopamine levels, and have shown that a reduction in the reuptake of dopamine, which DAT is responsible for, results in adapted changes, such as reduced dopamine levels in the presynaptic terminals, i.e. more dopamine remains in the synaptic cleft (Congdon \& Canli 2008). Due to its specific location, this polymorphism cannot influence the structure of the DAT protein, though it can impact the expression of the level of modulating structure or degradation of mRNA (Fuke et al. 2001). However, research on the association between the 9- and 10-repeat alleles with DAT1 gene expression has given inconsistent results. Namely, some studies have shown that the 9repeat allele is associated with greater DAT1 gene expression, and that those possessing the 9-repeat allele have greater accessibility to the DAT protein (Miller \& Madras 2002, Van Dyck et al. 2005). Other studies, however, indicate higher DAT1 gene expression in those possessing the 10-repeat allele, and that homozygotes (10/10) have excessive levels of the DAT protein (Brookes et al. 2007, Swanson et al. 2000). Finally, several studies have found that there is no functional significance of the DAT1 VNTR on the DAT enzyme (Martinez et al. 2001, Mill et al. 2005).

The gene that codes COMT is found on the 22nd chromosome, at the site 22q11.21 (Mrazek 2010). The gene is about $27 \mathrm{Kbp}$ long and 345 polymorphisms have been identified to date (Calati et al. 2011). The most commonly studied COMT gene polymorphism is SNP or Val158Met polymorphism (rs4680), in which a single G/A nucleotide substitution at the codons 108 and 158 result in a valine to methionine substitution (Rujescu et al. 2003), impacting the regulation of dopamine in the prefrontal cortex (Hashimoto et al. 2007). The valine (Val) to methionine (Met) substitution reduces thermostability and enzyme activity, translating the Met158 alelle into a thermally unstable enzyme associated with weaker activity, and thus with higher levels of extracellular dopamine (Schmack et al. 2008, DeYoung et al. 2011). The Val/Met genotype results in moderate COMT activity (Ishii et al. 2007), since the alleles are codominant. Further, Chen et al. (2004) showed that COMT activity in the prefrontal cortex is $40 \%$ higher in persons with the Val allele than in those with the Met allele, suggesting that the Val allele affects a decline in the synaptic levels of dopamine (and noradrenaline) in that region of the brain, through increased degradation of these catecholines (Lachman et al. 1996, Weinshilboum et al. 1999). However, Ishii et al. (2007) emphasized that the effects of the COMT polymorphism on synaptic levels of dopamine have not yet been fully elucidated, and that it is possibly too early to conclude whether the Val allele induces lower dopamine levels. It is also believed that the links between this polymorphism and catecholine transmission are much more complicated than they appear.
In terms of testing the relationships between personality and the COMT Val158Met polymorphism, an association has often been found between increased novelty seeking and the Met allele (e.g. Davila et al. 2013, Demetrovics et al. 2010), though some studies have also found links between novelty seeking and the Val allele (e.g. Reuter \& Hening 2005, Tsai et al. 2004). Associations have also been found between the Met allele and aggression (Rujescu et al. 2003), anxiety (Fernandez de Las Penas et al. 2012, Olsson et al. 2005) and extraversion (Reuter \& Henning 2005). The Val allele is associated with cooperativeness (Baeken et al. 2014), aggression (Flory et al. 2007, according to Calati et al. 2011) and schizotypal traits (Schurhoff et al. 2007, according to Calati et al. 2011). However, it should be stated that reports concern only certain personality traits, and that the results are truly variable. In comparison with research on personality traits associated with the COMT Val158Met polymorphism, there are fewer studies investigating the DAT1 VNTR polymorphism. Of the 30 papers reviewed, only a handful found an association between the same trait and the same genotype. For example, associations were found between novelty seeking and the 10/10 genotype, though some studies found an association with increased novelty seeking (Schosser et al. 2010) while others found an association with decreased novelty seeking (Anghelescu et al. 2010). Important VTA dopaminergic projections involve the amygdala, the hippocampus, the cingulate, and the PFC. Practically all of these VTA projections are reciprocal feedback connections, suggesting that dopamine has a role in modulating higher order cognitive functions of the neocortex, as well as the subcortical limbic areas involved in novelty and rewardbased learning. Perhpas this complexity can explain the variability of results regarding relationship between novelty seeking and dopaminergic genes presented here, whether we discuss about different levels of novelty seeking or different alleles of the same gene (and the same level of novelty seeking). Furthermore, the 10repeat allele is also associated with persistence (Kazantseva et al. 2011), self-directedness (Anghelescu et al. 2010) and risk-taking (Mata et al. 2012). The 9-repeat allele was found to be associated with impulsiveness (Joyce et al. 2009, Forbes et al. 2009) and novelty seeking (Schosser et al. 2010).

No studies of this type, to test the associations between personality and these polymorphisms, have been previously conducted in Croatia. The objective of this study was to test the association of the Cloninger temperament and character traits with the DAT1 VNTR and COMT Val158Met polymorphisms. As previously stated, Cloninger (1987) published the theory of the negative association between novelty seeking and dopamine levels. Since the Val allele is associated with increased activity of the COMT enzyme, and therefore with lower dopamine levels, for the purpose of testing the Cloninger assumptions, the following hypothesis was set: 
- Carriers of the Val/Val genotype have a higher novelty seeking trait in comparison to carriers of the $\mathrm{Val} / \mathrm{Met}$ and Met/Met genotypes, and carriers of the Val allele in comparison to carriers of the Met/Met genotype.

\section{SUBJECTS AND METHODS}

\section{Participants}

The study was conducted on a sample of 114 participants recruited among Police college students $(\mathrm{N}=56)$ and Sestre Milosrdnice University Hospital staff $(\mathrm{N}=58)$ in Zagreb. The mean age of participants was 35 years $(\mathrm{SD}=10.06)$, with $56.7 \%$ of participants being male and $43.3 \%$ female. A physical status exam was performed by a trained medical professional and the M.I.N.I. psychiatric interview (Mini International Neuropsychiatric Interview) (Sheenan 1998) was used to screen for potential mental disorders. Participants with extreme EPQ scores were also excluded. A total of 13 of the 114 participants were excluded from the study. DAT1 VNTR polymorphism was successfully genotyped for 91 and COMT Val158Met polymorphism for 92 participants. All participants willingly gave their informed consent to participate in this study. Firstly, they were informed about the scientific purpose of the study and about the means of securing anonymity with codes.

\section{Genotyping}

Genomic DNA was isolated from $200 \mu \mathrm{L}$ whole blood taken into K3EDTA eprouvettes (Greiner BioOne GmbH, Kremsmünster, Austria) using a commercial kit, High Pure PCR Template Preparation Kit (Roche, Basel, Switzerland).

\section{DAT1 VNTR polymorphism}

PCR multiplication was performed by the method originally described by Vandenbergh et al. (1992), using the primers DATf: 5'-TGTGGTGTAGGGAACGGCCTGAG-3' and DATr: 5'-CTTCCTGGAGGTCACGGCTCAAGG-3'. $30 \mu \mathrm{L}$ of PCR product consisted of $200 \mathrm{nmol} / \mathrm{L}$ DATf and DATr primers (Invitrogen, Carslbad, CA SAD), 200 $\mu \mathrm{mol} / \mathrm{L}$ of each dNTP, $1 \mathrm{U}$ Taq DNA polymerase, 1.5 $\mathrm{mmol} / \mathrm{L} \mathrm{Mg}$ in a matching PCR buffer with $1 \mathrm{X}$ concentration (Roche, Basel, Switzerland) $6 \% \mathrm{v} / \mathrm{v}$ DMSO and $100 \mathrm{ng}$ genomic DNA. Conditions for PCR multiplications (MasterCycler Gradient, Eppendorf, Hamburg, Germany) were: initial denaturation $-95^{\circ} \mathrm{C} / 2 \mathrm{~min}$; extension - 35 cycles $-95^{\circ} \mathrm{C} / 60 \mathrm{~s}, 68^{\circ} \mathrm{C} / 60 \mathrm{~s}, 72^{\circ} \mathrm{C} / 60 \mathrm{~s}$; final elongation $-72^{\circ} \mathrm{C} / 10 \mathrm{~min}$. PCR product was electrophoresed on a 2\% Biozym Sieve GP agarose gel (Biozym Scientific GmbH, Hessisch Oldendorf, Germany) at $100 \mathrm{~V} / \mathrm{cm}$ for 30 minutes and stained with ethidium bromide following the standard protocol. VNTR polymorphism was evaluated by comparison with marker XIII (Roche, Basel, Switzerland): VNTR 11 repeats $(520 \mathrm{pb})$, VNTR 10 repeats $(483 \mathrm{pb})$, VNTR 9 repeats $(441 \mathrm{pb})$, VNTR 7 repeats $(361 \mathrm{pb})$, VNTR 6 repeats $(321 \mathrm{pb})$.

\section{COMT Val158Met polymorphism}

PCR multiplication was performed by the method described by Lachman et al. (1996), using the primers COMTf: 5'-CTCATCACCATCGAGATCAA-3' and COMTr: 5'- CAGTGAACGTGGTGTGAACAC-3'). 30 $\mu \mathrm{L}$ of PCR product consisted of $200 \mathrm{nmol} / \mathrm{L}$ COMTf and COMTr primers (Invitrogen, Carslbad, CA SAD), $200 \mu \mathrm{mol} / \mathrm{L}$ of each dNTP, 1U Taq DNA polymerase, $1.5 \mathrm{mmol} / \mathrm{L} \mathrm{Mg}$ in a matching PCR buffer with $1 \mathrm{X}$ concentration (Roche, Basel, Switzerland) and $100 \mathrm{ng}$ genomic DNA. Conditions for PCR multiplications (MasterCycler Gradient, Eppendorf, Hamburg, Germany) were: initial denaturation $-94^{\circ} \mathrm{C} / 2 \mathrm{~min}$; extension - 35 cycles - $94^{\circ} \mathrm{C} / 30 \mathrm{~s}, 60^{\circ} \mathrm{C} / 30 \mathrm{~s}, 72^{\circ} \mathrm{C} / 120 \mathrm{~s}$; final elongation $-72^{\circ} \mathrm{C} / 10 \mathrm{~min}$. Following the electrophoresis control of successful multiplication, $10 \mu \mathrm{L}$ of PCR product was split at $37^{\circ} \mathrm{C}$ overnight with $6 \mathrm{U}$ NlaIII restriction enzyme (New England BioLabs, Ipswich$\mathrm{MA}, \mathrm{USA})$ in a matching buffer (1.2 $\mathrm{X}$ final concentration) and electrophoresed on Spreadex EL 300 gel (Elchrom Scientific AG, Cham, Switzerland) at $100 \mathrm{~V} / \mathrm{cm}$ for 50 minutes. Following staining with SYBR $^{\circledR}$ Gold (Invitrogen, Carslbad, CA USA), COMT polymorphism was evaluated in comparison to marker V (Roche, Basel, Switzerland). Val158 splits into fragments of $87 \mathrm{bp}, 54 \mathrm{bp}$ and $43 \mathrm{bp}$; while $158 \mathrm{Met}$ splits into fragments of $69 \mathrm{bp}, 54 \mathrm{bp}, 43 \mathrm{bp}$ and $18 \mathrm{bp}$.

\section{Instruments}

The TCI personality test (Cloninger et al. 1994) was used to measure personality. This test consists of 7 scales and 240 items, of which 40 measure novelty seeking (NS), 35 harm avoidance (HA), 32 reward dependence (RD), 8 persistence $(\mathrm{P}), 44$ self-directedness (SD), 42 cooperativeness (C) and 33 self-transcendence (ST). Participants responded to each item with true or false. Each scale consists of several subscales. NS consists of 4 subscales: exploratory excitability vs. stoic rigidness (NS1), impulsiveness vs. reflectiveness (NS2), extravagance vs. reservation (NS3), disorderliness vs. order (NS4). HA consists of 4 subscales: anticipatory worry and pessimism vs. uninhibited optimism (HA1), fear of uncertainty (HA2), shyness (HA3), fatigability and asthenia (HA4). RD consists of 3 subscales: sentimentality (RD1), openness to warm communication (RD2), attachment (RD3), dependence (RD4). P includes only one scale. SD consists of 5 subscales: responsibility vs. blame (SD1), purposeful vs. lack of focus (SD2), resourcefulness (SD3), self-acceptance (SD4), enlightened second nature (SD5). C consists of 5 subscales: social acceptance vs. social intolerance (C1), empathy vs. social disinterest (C2), helpfulness vs. unhelpfulness (C3), compassion vs. vengefulness (C4), pure-hearted conscience vs. care for own benefit (C5). Finally, ST consists of 3 subscales: spiritual acceptance vs. rational materialism (ST1), self-forgetful vs. awareness of lived experiences (ST2), transpersonal identification vs. self-differentiation (ST3). 
The TCI questionnaire was not validated for the Croatian population, and therefore, an analysis of the main components was performed and the reliability verified for the scales and subscales of that questionnaire. Parallel analysis (Monte Carlo PCA for Parallel Analysis) was used as the criteria to determine the number of main components. The expected factorial structure (four factors of temperament and three characters) was not confirmed, neither by the Kaiser criteria, nor by parallel analysis. The expected structure was visible only in the Scree plots, which is not sufficient as confirmation. In terms of reliability of the scales and subscales of the TCI questionnaire, satisfactory $\alpha$ coefficients were obtained in virtually all scales, ranging from 0.71 to 0.86 . For the subscales, the $\alpha$ coefficients ranged from 0.27 to 0.85 .

\section{Procedure}

Police college students completed the assessment at the college premises after their regular lectures. Sestre Milosrdnice Clinical Hospital (SMCH) employees completed the assessment at their workplace during their daily work pause. They then completed personality inventories, after which they willingly gave blood samples to trained medical staff from SMCH in Zagreb. Blood samples and questionnaires were coded and only the chief investigator had knowledge about which code corresponded to a specific participant.

\section{Statistical analysis}

The data was processed using the SPSS program package 18.0 (IBM SPSS Software). Relationship of personality traits and DAT1 VNTR and COMT Val158Met polymorphism genotypes was analysed by two-factor variance analysis.

Considering that the study also determined gender and age differences concerning personality traits (viz. Allemand, Zimprich \& Hendriks 2008, Chapman et al. 2007), prior to analysis, the dependent variables (personality traits) were corrected for the main effects of age and gender by regression.

Bonferroni's correction was not performed on the obtained results, as this procedure would be excessively strict for the sample size, and would cancel out significance, portraying truly significant results as insignificant. Therefore, this would result in increased exposure to type II errors.

Three types of variables for each polymorphism were analysed separately (along with other the polymorphism as an independent variable) with personality traits as the dependent variables. Those three types of variables were: independent three-level variables (DAT3 and COMT3) and two two-level independent variables (DAT9 and DAT10; COMTMet and COMTVal). The DAT1 VNTR polymorphism threelevel independent variable (DAT3) consisted of 9/9, 9/10 and 10/10 genotypes. The first two-level inde- pendent variable (DAT9) assumed the comparison of 9 allele carriers (9/9 and 9/10) with 10/10 genotype carriers, i.e. the differences between 9 allele carriers and those without it were analysed. The second twolevel independent variable (DAT10) assumed the comparison of 10 allele carriers $(9 / 10$ and $10 / 10)$ with 9/9 genotype carriers, i.e. the differences between 10 allele carriers and those without it were analysed. The COMT Val158Met polymorphism three-level independent variable (COMT3) consisted of Met/Met, Val/Met and Val/Val genotypes. The first two-level independent variable (COMTMet) assumed the comparison of Met allele carriers (Met/Met and Val/Met) with Val/Val genotype carriers, i.e. the differences between Met allele carriers and those without it were analysed. The second independent two-level variable (COMTVal) assumed the comparison of Val allele carriers (Val/Met and Val/Val) with Met/Met genotype carriers, i.e. the differences between Val allele carriers and those without it were analysed. The significance level of $p<0.05$ was considered to be statistically significant. The Hardy-Weinberg principle was tested using the on-line calculator

(http://www.had2know.com/academics/hardyweinberg-equilibrium-calculator-2-alleles.html).

\section{RESULTS}

Descriptive data of the study sample are presented in Table 1.

Table 1. Arithmetic mean and standard deviation of temperament and character traits, age and gender

\begin{tabular}{lccc}
\hline & N & M & SD \\
\hline Novelty seeking (NS) & 93 & 18.69 & 5.31 \\
Harm avoidance (HA) & 94 & 11.77 & 5.71 \\
Persistence (PS) & 98 & 4.48 & 2.01 \\
Reward dependence (RD) & 97 & 13.73 & 3.53 \\
Self-directedness (SD) & 94 & 32.92 & 7.00 \\
Cooperativeness (C) & 93 & 31.84 & 5.57 \\
Self-transcendence (ST) & 95 & 12.13 & 6.31 \\
Age & 94 & 34.59 & 10.06 \\
Gender & $\mathrm{f}$ & $\%$ & \\
$\quad$ M & 55 & 56.7 & \\
$\quad$ F & 42 & 43.3 & \\
\hline
\end{tabular}

In the sample of 101 participants, the distribution of the DAT1 VNTR genotypes was as follows: 9/9 - 6.6\%; $9 / 10-46.2 \%$, and $10 / 10-47.3 \%$. Allele frequencies were: $29.67 \%$ for the 9 -repeat allele, and $70.33 \%$ for the 10-repeat allele. The distribution of the COMT Val158Met genotypes was as follows: Met/Met 28.3\%, Val/Met $52.2 \%$ and Val/Val $19.6 \%$. The allele frequencies were: $45.65 \%$ for the Val allele, and $54.35 \%$ for the Met allele. The results are in accordance with the Hardy-Weinberg law $\left(\chi^{2} \mathrm{DAT} 1 \mathrm{VNTR}=29.29, \mathrm{df}=2\right.$, $\mathrm{p}=0.31 ; \chi^{2}$ COMT Val158Met $=15.73, \mathrm{df}=2, \mathrm{p}=0.62$ ). 
Table 2. Results of the ANOVA analysis for the DAT1 VNTR and COMT Val158Met in comparison to the dependent variables (DV) - NS3, SD2, SD3, C2, C3 and ST3

\begin{tabular}{|c|c|c|c|c|c|c|}
\hline Polymorphisms & DV & DF & $\mathrm{F}$ & Size effect & Strength & $\mathrm{p}$ \\
\hline DAT10 & NS3 & 1 & 1.26 & 0.01 & 0.19 & 0.26 \\
\hline COMTVal & & 1 & 5.46 & 0.06 & 0.63 & $0.02 *$ \\
\hline DAT10* COMTVal & & 1 & 5.91 & 0.06 & 0.67 & $0.01 *$ \\
\hline DAT10 & SD2 & 1 & 5.22 & 0.05 & 0.61 & $0.02 *$ \\
\hline COMTMet & & 1 & 0.00 & 0.00 & 0.05 & 0.93 \\
\hline DAT10* COMTMet & & 0 & & 0.00 & & \\
\hline DAT9 & SD3 & 1 & 0.17 & 0.00 & 0.06 & 0.67 \\
\hline COMTMet & & 1 & 4.82 & 0.05 & 0.58 & $0.03 *$ \\
\hline DAT9 $*$ COMTMet & & 1 & 0.91 & 0.01 & 0.15 & 0.34 \\
\hline DAT9 & $\mathrm{C} 2$ & 1 & 0.62 & 0.00 & 0.12 & 0.43 \\
\hline COMTVal & & 1 & 0.55 & 0.00 & 0.11 & 0.46 \\
\hline DAT9 * COMTVal & & 1 & 7.28 & 0.07 & 0.76 & $0.00 * *$ \\
\hline DAT9 & $\mathrm{C} 3$ & 1 & 0.04 & 0.00 & 0.05 & 0.83 \\
\hline COMTVal & & 1 & 4.36 & 0.04 & 0.54 & $0.04 *$ \\
\hline DAT9 $*$ COMTVal & & 1 & 0.99 & 0.01 & 0.16 & 0.32 \\
\hline DAT9 & ST3 & 1 & 3.87 & 0.04 & 0.49 & 0.05 \\
\hline COMTVal & & 1 & 5.12 & 0.05 & 0.60 & $0.02 *$ \\
\hline DAT9 $*$ COMTVal & & 1 & 5.14 & 0.05 & 0.61 & 0.06 \\
\hline
\end{tabular}

${ }^{* p}<0.05 ; \quad * * \mathrm{p}<0.01 ; \quad$ DAT9=9/9 and $9 / 10$ vs. $10 / 10 ; \quad$ DAT10=10/10 and 9/10 vs. 9/9; COMTVal=Val/Val and $\mathrm{Val} / \mathrm{Met}$ vs. Met/Met; COMTMet=Met/Met and Val/Met vs. Val/Val; NS3=extravagance vs. reservation; SD2=purposefulness vs. lack of focus; $\mathrm{SD} 3=$ resourcefulness; $\mathrm{C} 2=$ empathy vs. social disinterest; $\mathrm{C} 3=$ helpfulness vs. unhelpfulness; ST3= transpersonal identification vs. self-differentiation

Table 3. Descriptive data for COMT Val158Met and DAT1 VNTR

\begin{tabular}{|c|c|c|c|c|c|}
\hline Polymorphisms & DV & Level & M & SD & $\mathrm{N}$ \\
\hline \multirow[t]{2}{*}{ COMTVal (COMTVal and DAT10) } & NS3 & $\mathrm{Val} / \mathrm{Val}, \mathrm{Val} / \mathrm{Met}$ & 5.03 & 2.22 & 63 \\
\hline & & Met/Met & 4.76 & 2.37 & 26 \\
\hline \multirow[t]{2}{*}{ DAT10 (DAT10 and COMTMet) } & SD2 & $10 / 10,9 / 10$ & 6.02 & 1.36 & 83 \\
\hline & & $9 / 9$ & 7.33 & 0.51 & 6 \\
\hline \multirow[t]{2}{*}{ COMTMet (COMTMet and DAT9) } & SD3 & Met/Met, Val/Met & 3.80 & 1.31 & 72 \\
\hline & & Val/Val & 4.50 & 0.78 & 18 \\
\hline \multirow[t]{2}{*}{ COMTVal (COMTVal and DAT9) } & $\mathrm{C} 3$ & $\mathrm{Val} / \mathrm{Val}, \mathrm{Val} / \mathrm{Met}$ & 5.68 & 1.11 & 64 \\
\hline & & Met/Met & 5.08 & 1.25 & 25 \\
\hline \multirow[t]{2}{*}{ COMTVal (COMTVal and DAT9) } & ST3 & $\mathrm{Val} / \mathrm{Val}, \mathrm{Val} / \mathrm{Met}$ & 2.69 & 1.84 & 62 \\
\hline & & Met/Met & 3.46 & 2.37 & 26 \\
\hline
\end{tabular}

DAT9=9/9 and 9/10 vs. 10/10; DAT10=10/10 and 9/10 vs. 9/9; COMTVal=Val/Val and Val/Met vs. Met/Met;

COMTMet=Met/Met and Val/Met vs. Val/Val; NS3=extravagance vs. reservation; SD2=purposefulness vs. lack of focus; $\mathrm{SD} 3=$ resourcefulness; $\mathrm{C} 2=$ empathy vs. social disinterest; $\mathrm{C} 3=$ helpfulness vs. unhelpfulness; $\mathrm{ST} 3=$ transpersonal identification vs. self-differentiation

Table 4. Results of the analysis of simple effects of the interaction effects of DAT1 VNTR and COMT Val158Met in relation to the dependent variables NS3 and C2

\begin{tabular}{|c|c|c|c|c|c|c|c|c|c|}
\hline Polymorphisms, DV & Source of variation & Level & & $\mathrm{M}$ & SD & $\mathrm{N}$ & DF & $\mathrm{F}$ & $\mathrm{p}$ \\
\hline $\begin{array}{l}\text { DAT10 } \\
\text { COMTVal }\end{array}$ & $\begin{array}{l}\text { COMTVal } \\
\text { within }\end{array}$ & $\begin{array}{l}\text { COMTVal } \\
\text { DAT10 }\end{array}$ & $\begin{array}{l}\mathrm{Val} / \mathrm{Met}, \mathrm{Val} / \mathrm{Val} \\
10 / 10\end{array}$ & 6.25 & 2.21 & 4 & 1 & 4.97 & $0.02 *$ \\
\hline ZV: NS3 & DAT10 $(10 / 10)$ & $\begin{array}{l}\text { COMTVal } \\
\text { DAT10 }\end{array}$ & $\begin{array}{l}\text { Met/Met } \\
10 / 10\end{array}$ & 1.50 & 0.70 & 2 & & & \\
\hline $\begin{array}{l}\text { COMTVal } \\
\text { DAT9 }\end{array}$ & $\begin{array}{l}\text { COMTVal } \\
\text { within }\end{array}$ & $\begin{array}{l}\text { COMTVal } \\
\text { DAT9 }\end{array}$ & $\begin{array}{l}\mathrm{Val} / \mathrm{Val}, \mathrm{Val} / \mathrm{Met} \\
10 / 10\end{array}$ & 4.54 & 1.66 & 33 & 1 & 4.33 & $0.04 *$ \\
\hline $\mathrm{ZV}: \mathrm{C} 2$ & DAT9 $(10 / 10)$ & $\begin{array}{l}\text { COMTVal } \\
\text { DAT9 }\end{array}$ & $\begin{array}{l}\text { Met/Met } \\
10 / 10\end{array}$ & 5.66 & 0.50 & 9 & & & \\
\hline
\end{tabular}
$* p<0.05 ; \quad * * p<0.01 ; \quad$ DAT $10=10 / 10$ and $9 / 10$ vs. $9 / 9 ; \quad$ DAT9=9/9 and 9/10 vs. $10 / 10 ; \quad$ COMTVal=Val/Val and $\mathrm{Val} / \mathrm{Met}$ vs. Met/Met; NS3=extravagance vs. reservation; $\mathrm{C} 2=$ empathy vs. social disinterest 
Table 2 shows that of all the analyses of variance for each dimension of temperament and character, several main effects were found for both polymorphisms and their interactive effects. A significant effect of DAT1 VNTR was found on the self-determined scale (SD2 subscale - purposefulness vs. lack of focus; $\mathrm{F}=5.18, \mathrm{df}=1$, $\mathrm{p}<0.05$ ), and a significant effect of COMTVal158Met on the scales: novelty seeking (subscale NS3 - extravagance vs. reservation; $\mathrm{F}=5.18, \mathrm{df}=1, \mathrm{p}<0.05$ ), self-determinedness (subscale SD3 - resourcefulness; $\mathrm{F}=5.18$, $\mathrm{df}=1, \mathrm{p}<0.05$ ), cooperativeness (subscale $\mathrm{C} 3$ - helpfulness vs. unhelpfulness; $(\mathrm{F}=5.18, \mathrm{df}=1, \mathrm{p}<0.05)$ and selftranscendence (subscale ST3 - transpersonal identification vs. self-differentiation; $(\mathrm{F}=5.18, \mathrm{df}=1, \mathrm{p}<0.05)$. Interactive effects of the two polymorphisms was found on the novelty seeking scale (subscale NS3 - extravagance vs. reservation; $\mathrm{F}=5.18, \mathrm{df}=1, \mathrm{p}<0.05)$ and cooperativeness (subscale $\mathrm{C} 2$ - empathy vs. social disinterest; $\mathrm{F}=5.18, \mathrm{df}=1, \mathrm{p}<0.05)$.

Furthermore, in terms of the main effect of DAT1 VNTR, a higher result was found on the subscale selfdirectedness (SD2) among carriers of the 9/9 genotype $(\mathrm{M}=7.33, \mathrm{SD}=0.51$, Table 3$)$ than in carriers of the 10 repeat allele $(\mathrm{M}=6.02, \mathrm{SD}=1.36)$. For the main effect of COMTVal158Met, a higher result was found on the subscale novelty seeking (NS3) among carriers of the Val allele $(\mathrm{M}=5.03, \mathrm{SD}=2.22)$ than those carrying the Met/Met genotype $(\mathrm{MD}=4.76, \mathrm{SD}=2.37)$. A higher result on the subscale self-directedness (SD3) was found among carriers of the $\mathrm{Val} / \mathrm{Val}$ genotype $(\mathrm{M}=4.50$, $\mathrm{SD}=0.78$ ) than carriers of the Met allele (Met/Met, Val/Met $)(\mathrm{M}=3.80, \mathrm{SD}=1.31)$. A higher result on the subscale cooperativeness (C3) was found among carriers of the Val allele $(\mathrm{M}=5.68, \mathrm{SD}=1.25)$ than carriers of the Met/Met genotype $(\mathrm{M}=5.08, \mathrm{SD}=1.11)$. A higher result on the subscale self-transcendence (ST3) was found among carriers of the Met/Met genotype $(\mathrm{M}=3.46, \mathrm{SD}=2.37)$ than carriers of the Val allele $(\mathrm{M}=2.69, \mathrm{SD}=1.84)$.

In the figures (Figure 1 and 2), the joint effects of the polymorphisms can be seen for novelty seeking (subscale NS3) and cooperativeness (subscale C2). However, for a more detailed analysis, simple effects analysis was performed (Table 4). The effect of each level of one independent variable on levels of other independent variables was tested.

With regard to the interactions of DAT10 and COMTVal on the subscale novelty seeking (NS3), carriers of the Val allele and the 10/10 genotype $(\mathrm{M}=6.25, \mathrm{SD}=2.21$, Table 4) had a higher result that carriers of the Met/Met and 10/10 genotypes $(M=1.50$, $\mathrm{SD}=0.70$ ). The remaining combinations of various levels of either independent variable did not yield statistically significant results. For the interaction of COMTVal and DAT9 (C2), a higher result was seen among carriers of the Met/Met and 10/10 genotypes $(\mathrm{M}=5.66, \mathrm{SD}=0.50)$ than carriers of the Val allele and $10 / 10$ genotype $(M=4.54, S D=1.66)$. The remaining combinations of levels for either independent variable did not yield statistically significant results. In the analysis of COMTVal and DAT9, the Leven test was significant $(<0.05 ; 0.00)$, and therefore the results of that analysis should be interpreted with caution.

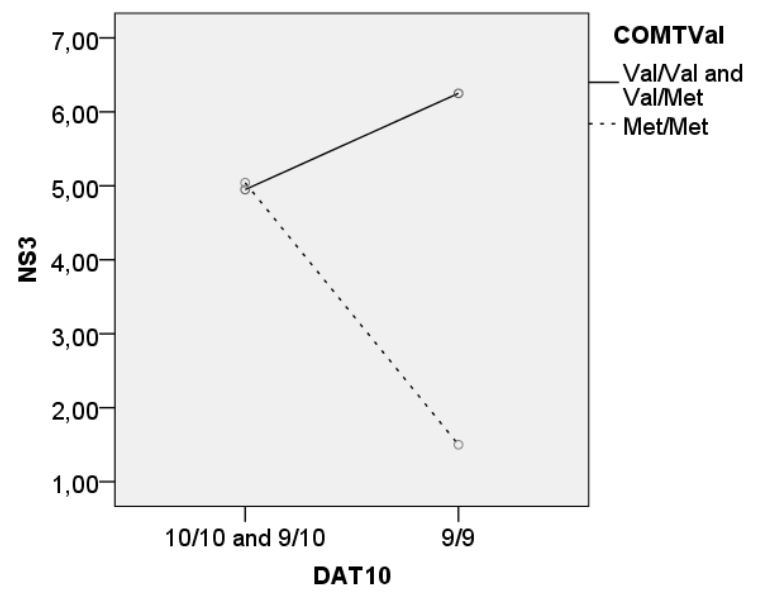

Figure 1. Graphic depiction of the interactive effects of DAT1 VNTR and COMTVal158Met

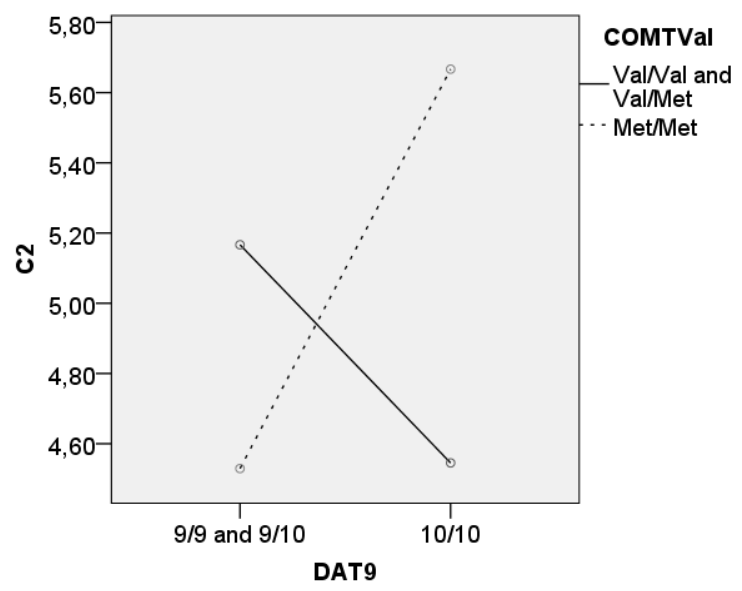

Figure 2. Graphic depiction of the interactive effects of DAT1 VNTR and COMTVal158Met

Cloninger's (1987) hypothesis of a negative association between novelty seeking and dopamine levels was partially confirmed in the context of COMT Val158Met, at the allele level. No significant main effect was obtained for COMT Val158Met in the analysis with the entire NS scale as the dependent variable, which included three types of COMT variables (COMT3, COMTMet and COMTVal). For the subscales, no significant main effect was obtained for COMT3 as the independent variable on any of the subscales, though a main effect of COMTVal (Val/Val and $\mathrm{Val} / \mathrm{Met}$ vs. Met/Met) as the independent variable was obtained for NS3. Therefore, greater novelty seeking was found among carriers of the Val allele in comparison with those carrying the Met/Met genotype, thereby partially confirming the Cloninger hypothesis. 


\section{DISCUSSION}

The results of the study showed that there is a statistically significant main effect of the tested polymorphisms, and their interactive effect on the results of the temperament and character scales.

The subscale of purposefulness vs. lack of focus (self-directedness) showed a main effect of DAT1 VNTR, and a higher result was found for carriers of the 9/9 genotype than for carriers of the 10-repeat allele. For the COMT Val158Met polymorphism, main effects were found on the subscales: extravagance vs. reservation (novelty seeking), where Val allele carriers had a higher result than Met/Met genotype carriers; persistence (self-directedness), where Val/Val genotype carriers had a higher result than Met allele carriers; helpfulness vs. unhelpfulness (cooperativeness), where Val allele carriers had a higher result than the Met/Met genotype carriers, and on the subscale of transpersonal identification vs. self-differentiation (self-transcendence), where Met/Met genotype carriers had a higher result than Val allele carriers. Two significant interactions were also found. On the subscale of extravagance vs. reservation (novelty seeking), Val allele and 10/10 genotype carriers had a higher result than the Met/Met and 10/10 genotype carriers. On the subscale of empathy vs. social disinterest (cooperativeness), a higher result was found for Met/Met and 10/10 genotype carriers than Val allele and 10/10 genotype carriers.

For the purpose of this study, a comprehensive review was performed of research (published to 2015) testing the associations of personality with the polymorphisms tested here. For DAT1 VNTR and selfdirectedness, the study of Anghelescua et al. (2010) found results contrary to those presented here.

For COMT Val158Met and novelty seeking, several studies reported contrary results to those presented here (Hosak et al. 2006, Davila et al. 2013, Demetrovics et al. 2010, Golimbet et al. 2007). However, two studies reported results corroborated by those in the present study (Reuter \& Henning 2005, Tsai et al. 2004). For cooperativeness and COMT Val158Met, a larger number of studies was found to report an association between these two variables (Baekken et al. 2014, Hori et al. 2014, Mikolajczyk et al. 2009, Reuter et al. 2010). The results of this study corroborate those of Reuter et al. (2010). For self-directness, our results corroborate those of Mikolajczyka et al. (2009). For self-transcendence and the tested polymorphisms, no papers were found to give similar results to those presented here.

For the interactions, no studies in the literature reported results similar to those reported here. However, it is necessary to state that interactions have weaker statistical strength than the main effects, and therefore the interpretation of statistically significant interactions should be addressed with greater caution, and those results verified on a larger sample size.
Cloninger's (1987) hypothesis on the negative associations between novelty seeking and dopamine levels was partially confirmed in the context of COMT Val158Met. No significant main effects of COMT Val158Met were obtained in the analysis of the overall novelty seeking scale. However, on the subscale extravagance vs. reservation, a significant main effect was found, with carriers of the Val allele having higher results in comparison with carriers of the Met/Met genotype, thereby confirming Cloninger's hypothesis at the allele level.

The present study had several limitations. Above all, a limitation was the result of the factorial analysis of the TCI personality questionnaire. As in other studies (e.g. Gana \& Troulliet 2003, Herbst et al. 2000, Tomita et al. 2000), this study did not have a suitable factorial structure. There are several variables that could affect the results of the study, such as race. Namely, allele frequency is differentiated by different ethnic and population groups. This study was performed exclusively on persons of Caucasian race, therefore the results cannot be generalised for other races. An important factor is environmental influence, such as the interaction of genes and the environment, i.e. exposure to various stressors, which were not controlled in this study. Sample size is another limitation of this study. Namely, the analysis of statistical strength and size of effects on the significant results suggests a very small effect (partial $\eta^{2}=0.09$; partial $\eta^{2}=0.06$ ) and unsatisfactory strength $(<0.80)$. Therefore, future studies should be performed on large samples, as sample size has a very direct and powerful effect on the statistical power of the test (McHugh 2008). Furthermore, the sample of this study consisted only of police employees and hospital staff, and therefore, it is questionable as to how these results could be generalised to the remainder of the population.

Cloninger did not exclude the existence of a genetic foundation for character, though he considered that genes were more involved in the foundation of personality traits (Cloninger, 1998). Later, he stressed that research on the biological foundation of characters had proven the existence of some heredity and association with specific genes (Cloninger 2003). Kirk (1999) stated that the additive genetic influences proved to be important in the sense of self-transcendence, and that heritability was assessed to range from 0.37 to 0.41 for both genders, and that the effects of the common environment did not prove to be significant. Namely, the literature reports findings, though few, of research connecting character traits with the tested polymorphisms (Hamer et al. 1999, Saiz et al. 2010, Thierry et al. 2004). This research has confirmed that there is a genetic foundation to character traits. Future studies could prove interesting to additionally test Cloninger's theory, with an analysis of the strength of association between genes and personality traits on the one hand, and the association with character on the other. 
In the late $1990 \mathrm{~s}$, molecular and genetic research of personality began, and numerous studies have since been performed. However, this subject area is highly complex and sensitive, with a large number of factors that could impact the results, and which should be controlled. Therefore, the numerous contradictory results, and the generally broad and diverse spectrum of results should come as no surprise. In the future, we can expect it will be possible to gain insight into a person's personality traits from a blood sample. We are still far from this, though this and similar studies are contributing toward that goal. Efforts certainly should be focused on standardising the work methodology. In addition to all the biological factors that impact these results, it is necessary to reduce the researcher's influence.

\section{CONCLUSIONS}

The objective of this study was to test the association between the Cloninger dimensions of temperament and character with the DAT1 VNTR and COMT Val158Met polymorphisms.

Main effects were found for both polymorphisms, and for their interactions. The main effect of the DAT1 VNTR polymorphism was found for the subscale of purposefulness vs. lack of focus (self-directedness), with a higher result found in carriers of the 9/9 genotype than in those carrying the 10-repeat allele. For the COMT Val158Met polymorphism, the main effects were found on the subscales: extravagance vs. reservation (novelty seeking), with a higher result among Val allele carriers than Met/Met genotype carriers; resourcefulness (self-directedness), with a higher result among $\mathrm{Val} / \mathrm{Val}$ genotype carriers than Met allele carriers; helpfulness vs. unhelpfulness (cooperativeness), with a higher result among Val allele carriers than Met/Met genotype carriers, and on the subscale transpersonal identification vs. self-differentiation (self-transcendence), with a higher result found among Met/Met genotype carriers than Val allele carriers. Two significant interactions were also found. On the subscale extravagance vs. reservation (novelty seeking), a higher result was found among carriers of the Val allele and 10/10 genotype than carriers of the Met/Met and 10/10 genotypes. On the subscale empathy vs. social disinterest (cooperativeness), a higher result was found among carriers of the Met/Met and 10/10 genotypes than carriers of the Val allele and 10/10 genotype.

At the allele level, Cloninger's (1987) hypothesis of a negative association between novelty seeking and dopamine levels was confirmed, in the context of COMT Val158Met, where greater novelty seeking was found among carriers of the Val allele in comparison with carriers of the Met/Met genotype.

\section{Acknowledgements:}

This work has been accomplished within the project „Molecular- Biochemical factors in patients with depressive disorder" led by PhD Full Professor Dalibor Karlović. The project has been fully supported by the Ministry of Science, Education and Sports of the Republic of Croatia under the project number 1340000000-3372.

\section{Conflict of interest: None to declare.}

\section{Contribution of individual authors:}

Ivana Glavina Jelaš \& Dalibor Karlović conceptualized and designed the study, participated in data collection, data interpretation and manuscript preparation;

Ivan Dević performed statistical analyses, was involved in multiple edits of the manuscript drafts and critically reviewed the manuscript as submitted.

\section{References}

1. Allemand M, Zimprich D, Hendriks AA: Age differences in five personality domains across the life span. Dev Psychol 2008; 44:758-770

2. Anghelescu I, Klawe C, Singer P, Fehr C, Hiemke C, Quante $A$ et al.: Low novelty seeking and high selfdirectedness scores in alcohol-dependent patients without comorbid psychiatric disorders homozygous for the A10 allele of the dopamine transporter gene. Biol Psychiatry 2010; 11:382-389

3. Baeken C, Claes S, De Raedt R: The influence of COMT Val158Met genotype on the character dimension cooperativeness in healthy females. Brain and Behavior 2014; 1-7

4. Bouchard TJ Jr \& Loehlin JC: Genes, evolution, and personality. Behav Genet 2001; 31:243-273

5. Brookes KJ, Neale BM, Sugden K, Khan N, Asherson P, D'Souza UM: Relationship between VNTR polymorphisms of the human dopamine transporter gene and expression in post-mortem midbrain tissue. Am J Med Genet 2007; 144:1070-1078

6. Calati R, Porcelli S, Giegling I, Hartmann AM, Möller H, De Ronchi $D$ et al.: Catechol-o-methyltransferase gene modulation on suicidal behavior and personality traits: review, meta-analysis and association study. J Psychiatr Res 2011; 45:309-321

7. Chapman BP, Duberstein PR, Sörensen S, Lyness JM: Gender differences in Five Factor Model personality traits in an elderly cohort. Personality and Individual Differences 2007; 43:1594-603

8. Chen J, Lipska BK, Halim N, Ma QD, Matsumoto M, Melhem $S$ et al: Functional analysis of genetic variation in catechol-O-methyltransferase (COMT): effects on $m R N A$, protein, and enzyme activity in postmortem human brain, Am J Hum Genet 2004; 75:807-821

9. Cloninger CR: A Systematic Method for Clinical Description and Classification of Personality Variants. Archives of General Psychiatry 1987; 44:573-588

10. Cloninger CR: Completing the Psychobiological Architecture of Human Personality Development: Temperament, 
Character, and Coherence. In Staudinger UM, Linderberger $U$ (eds): Understanding human development. Dialogues with Lifespan Psychology, 159-183. New York: Springer Science-Business Media, 2003

11. Cloninger CR, Przybeck TR, Svrakic DM, Wetzel RD: The Temperament and Character Inventory (TCI): A Guide to Its Development and Use. St. Louis, Washington University, 1994

12. Davila W, Basterreche N, Arrue A, Zamalloa MI, Gordo E, Davila R et all.: The Influence of the Val158Met Catechol-O-Methyltransferase Polymorphism on the Personality Traits of Bipolar Patients. PLoS One 2013; 8:1-7

13. Demetrovics Z, Varga G, Szekely A, Vereczkei A, Csorba $J$, Balaz H. et al.: Association between Novelty Seeking of opiate-dependent patients and the catechol-O-methyltransferase Val158Met polymorphism. Comprehensive Psychiatry 2010; 51:510-515

14. DeYoung CG, Cicchetti D, Rogosch FA, Gray JR., Eastman M, Grigorenko EL: Sources of cognitive exploration: Genetic variation in the prefrontal dopamine system predicts Openness/Intellect. Journal of Research in Personality 2011; 45:364-371

15. Fernandez de Las Penas C, Ambite-Quesada S, GilCrujera A, Cigaran-Mendez M, Penacoba-Puente C: Catechol-O-methyltransferase Val158Met polymorphism influences anxiety, depression, and disability, but not pressure pain sensitivity, in women with fibromyalgia syndrome. J Pain 2012; 13:1068-1074

16. Forbes EE, Brown SM, Kimak M, Ferrell RE., Manuck SB, Hariri AR: Genetic variation in components of dopamine neurotransmission impacts ventral striatal reactivity associated with impulsivity. Mol Psychiatry 2009; 14:60-70

17. Fuke S, Suo S, Takahashi N, Koike H, Sasagawa N, Ishiura $S$ : The VNTR polymorphism of the human dopamine transporter (DAT1) gene affects gene expression, The Pharmacogenomics Journal 2001; 1:152-156

18. Gana $K \&$ Trouillet $R$ : Structure invariance of the Temperament and Character Inventory (TCI). Personality and Individual Differences 2003; 35:1483-1495

19. Golimbet VE, Alfimova MV, Gritsenko IK, Ebstein RP: Relationship between dopamine system genes and extraversion and novelty seeking. Neurosci Behav Physiol 2007: 37:601-606

20. Hamer DH, Greenberg BD, Sabol SZ, Murphy DL: Role of the serotonin transporter gene in temperament and character. Journal of Personality Disorders 1999; 13:312-327

21. Hashimoto R, Noguchi H, Hori H, Ohi K, Yasuda Y, Takeda $M$ et al.: A possible association between the Val158Met polymorphism of the catechol-O-methyl transferase gene and the personality trait of harm avoidance in Japanese healthy subjects. Neurosci Lett 2007; 428:17-20

22. Hosak L, Libiger J, Cizek J, Beranek M, Cermakova E: The COMT Val158Met polymorphism is associated with novelty seeking in Czech methamphetamine abusers: preliminary results. Neuroendocrinology 2006; 27:799-802

23. Ishii G, Suzuki A, Oshino S, Shiraishi H, Matsumoto Y, Otani $K$ et al.: Association study of catechol-O-methyltransferase Val158Met polymorphism with personality traits in Japanese healthy volunteers. European Psychiatry 2007; 22:462-465

24. Joyce PR, McHugh PC, Light KJ, Rowe S, Miller AL, Kennedy MA: Relationships between Angry-Impulsive Personality Traits and Genetic Polymorphisms of the Dopamine Transporter. Biol Psychiatry 2009; 66:717-721
25. Kazantseva AV, Gaysina DA, Faskhutdinova GG, Noskova T, Malykh SB, Khusnutdinova EK: Polymorphisms of the serotonin transporter gene (5-HTTLPR, A/G SNP in 5HTTLPR, and STin2 VNTR) and their relation to personality traits in healthy individuals from Russia. Psychiatr Genet 2008; 18:167-76

26. Kirk KM, Eaves LJ, Martin NG: Self-transcendence as a measure of spirituality in a sample of older Australian twins. Twin Research 1999; 2:81-87

27. Lachman HM, Papolos DF, Saito T, Yu YM, Szymlanksi C, Weinshilboum RM: Human catechol-O-methyltransferase pharmacogenetics: description of a functional polymorphism and its potential application to neuropsychiatric disorders. Pharmacogenetics 1996; 6:243-250

28. Larsen RJ \& Buss DM: Personality Psychology. McGraw Hill, Boston, 2005

29. Larsen RJ \& Buss DM: Psihologija ličnosti. Naklada Slap, Jastrebarsko, 2008

30. Martinez D, Gelernter J, Abi-Dargham A, van Dyck CH, Kegeles $L$, Innis $R B$ et al.: The variable number of tandem repeats polymorphism of the dopamine transporter gene is not associated with significant change in dopamine transporter phenotype in humans. Neuropsychopharmacology 2001; 24:553-560

31. Mata R, Hau R, Papassotiropoulos A, Hertwig R: DAT1 Polymorphism Is Associated with Risk Taking in the Balloon Analogue Risk Task (BART). PLoS One 2012; 7:1-7

32. McHugh ML: Power analysis in research. Biochemia Medica 2008; 18:263-74

33. Mikolajczyk E, Grzywacz A, Samochowiec J: The association of catechol-O-methyltransferase genotype with the phenotype of women with eating disorders. Brain Res 2009; 142-148

34. Mill J, Asherson P, Craig I, D'Souza UM: Transient expression analysis of allelic variants of a VNTR in the dopamine transporter gene (DAT1). BMC Genetics 2005; 6:3-12

35. Miller GM \& Madras BK: novelty seeking Polymorphisms in the 3'-untranslated region of human and monkey dopamine transporter genes affect reporter gene expression. Mol Psychiatry 2002; 7:44-55

36. Mrazek DA: Psychiatric Pharmacogenomics. University Press, Oxford, 2010.

37. Olsson CA, Anney RJ, Lotfi-Miri M, Byrnes GB, Williamson $R$, Patton GC: Association between the COMT Val158Met polymorphism and propensity to anxiety in an Australian population-based longitudinal study of adolescent health. Psychiatr Genet 2005; 15:109-115

38. Reuter $M \&$ Hennig $J:$ Association of the functional catechol-O-methyltransferase VAL158MET polymorphism with the personality trait of extraversion. Neuroreport $2005 ; 16: 1135-1138$

39. Reuter M, Frenzel C, Walter NT, Markett S, Montag C: Investigating the genetic basis of altruism: the role of the COMT Val158Met polymorphism. Social Cognitive and Affective Neuroscience 2010; 6:662-668

40. Rujescu D, Giegling I, Gietl A, Hartmann AM, Moller H.: A functional single nucleotide polymorphism (V158M) in the COMT gene is associated with aggressive personality traits. Biol Psychiatry 2003; 54:34-39

41. Saiz PA, Garcia-Portilla MP, Herrero $R$, Arango $C$, Corcoran $P$, Morales $B$ et al.: Interactions between functional serotonergic polymorphisms and demographic factors influence personality traits in healthy Spanish Caucasians. Psychiatr Genet 2010; 20:171-178 
42. Schmack K, Schlagenhauf F, Sterzer P, Wrase J, Beck A, Dembler T et al.: Catechol-O-methyltransferase Val158Met genotype influences neural processing of reward anticipation. Neuro Image 2008; 42:1631-1638

43. Schosser A, Fuchs K, Scharl T, Schloegelhofer M, Kindler J, Mossaheb $N$ et al.: Interaction between serotonin 5-HT2A receptor gene and dopamine transporter (DAT1) gene polymorphisms influences personality trait of persistence in Austrian Caucasians. World J Biol Psychiatry 2010; 11:417-424

44. Sheenan, DV, Lecrubier Y, Sheenan KH, Amorim P, Janavs $J$, Weiller E et al: The Mini International Neuropcyhiatric Interview (M.I.N.I.): the development and validation of a structured diagnostic psychiatric interview for DSM-IV and ICD-10. J Clin Psychiatry 1998; 20:34-57

45. Swanson JM, Flodman P, Kennedy J, Spence MA, Moyzis $R$, Schuck $S$ et al.: Dopamine genes and ADHD. Neurosci Biobehav Rev 2000; 24:21-25

46. Thierry N, Willeit M, Praschak-Riedera N, Zillb P, Hornik $K$, Neumeister A et al.: Serotonin transporter promoter gene polymorphic region (5-HTTLPR) and personality in female patients with seasonal affective disorder and in healthy controls. Eur Neuropsychopharmacol 2004; 14:53-58

47. Tomita T, Aoyama H, Kitamura T, Sekiguchi C, Mutai T, Matsuda T: Factor structure of psychobiological sevenfactor model of personality: A model revision. Personality and Individual Differences 2000; 29:709-727
48. Tsai SJ, Hong CJ, Yu YW, Chen TJ: Association study of catechol-O-methyltransferase gene and dopamine D4 receptor gene polymorphisms and personality traits in healthy young Chinese females. Neuropsychobiology 2004; 50:153-156

49. Vandenbergh DJ, Persico AM, Hawkins AL, Griffin CA, $L i$ $X$, Jabs EW et al.: Human dopamine transporter gene (DAT1) maps to chromosome 5 p15.3 and displays a VNTR. Genomics 1992; 14:1104-1106

50. van Dyck CH, Malison RT, Jacobsen LK, Seibyl JP, Staley $J K$, Laruelle $M$ et al.: Increased Dopamine Transporter Availability Associated with the 9-Repeat Allele of the SLC6A3 Gene. J Nucl Med 2005; 46:745-751

51. VanNess SH, Owens MJ, Kilts CD: The variable number of tandem repeats element in DAT1 regulates in vitro dopamine transporter density. BMC Genet 2005; 6:55.

52. Vukasović T: Meta-analiza istraživanja genetskoga $i$ okolinskoga doprinosa individualnim razlikama u ličnosti (dissertation). Zagreb: University of Zagreb, Filozofski fakultet; 2013

53. Weinshilboum RM, Otterness DM, Szumlanski CL: Methylation pharmacogenetics: catechol O-methyltransferase, thiopurine methyltransferase and histamine $\mathrm{N}$ methyltransferase. Annu Rev Pharmacol Toxicol 1999; 39:19-52

Correspondence:

Ivan Dević, PhD

Ivo Pilar Institute of Social Sciences

Marulićev trg 19/1, Zagreb, Croatia

E-mail:ivan.devic@pilar.hr 